\title{
SELF-PROPAGATING HIGH-TEMPERATURE SYNTHESIS (SHS) OF COMPOSITE FERROALLOYS
}

\author{
I. M. Shatokhin ${ }^{1}$, M. Kh. Ziatdinov², I. R. Manashev³, O. P. Shiryaev ${ }^{4}$, A. D. Kartunov ${ }^{4}$ \\ ${ }^{1}$ NTPF "Etalon" (Magnitogorsk, Russia) \\ 2 Tomsk State University (Tomsk, Russia) \\ ${ }^{3}$ Nosov Magnitogorsk State Technical University (Magnitogorsk, Russia) \\ ${ }^{4}$ Magnitogorsk Iron and Steel Works (Magnitogorsk, Russia)
}

E-mail: mirney@yandex.ru

\section{AUTHOR'S INFO \\ Shatokhin I. M., General \\ Director; \\ Ziatdinov M. Kh., Dr. Eng., \\ Leading Researcher; \\ Manashev I. R., Cand. Eng.; \\ Shiryaev O. P., Deputy General \\ Director on Production; \\ Kartunov A. D., Head \\ of Technical Dept.}

A B S T R ACT
Key words:

self-propagating high-temperature synthesis, nitriding ferroalloys, ferrovanadium nitride, ferrochromium nitride, ferrosilicium nitride, filtration combustion, microalloying.

\begin{abstract}
The results of studies on the production of a new class of alloying materials in the combustion mode are presented on the example of synthesis of composite alloys based on vanadium, chromium and silicon nitrides. Principal possibility of creation of the SHS production of various composite ferroalloys for steelmaking was proved when using conventional ferroalloys as a raw material. It is shown that the degree of nitriding of ferroalloys in the conditions of filtration combustion strongly depends on the pressure of nitrogen, initial material powder dispersity and porosity of the nitride samples. The higher is the nitrogen pressure, the greater is the porosity of the samples and the larger are particles of the original ferroalloy powder, and the greater is the amount of nitrogen fixed in the combustion products. More dense samples and samples of the larger ferroalloy powder are nitrided in a more narrow range of nitrogen pressure. To initiate a stable layer-by-layer combustion it is required to provide higher pressure in such samples. It is shown that nitriding of initial ferroalloy can occur either by solid-phase (ferrochromium) or by liquid-phase (ferrosilicium, ferrovanadium) mechanisms, depending on the composition of initial ferroalloy. In the first case, the combustion temperature is below the melting point of the initial alloy and eutectic in the system $\mathrm{Cr}-\mathrm{Fe}-\mathrm{N}$. In the second case it is higher. When solid-phase nitriding takes place, ferroalloy saturation with nitrogen always occurs step-by-step - at layer-by-layer combustion and volumetric additional burning. When liquid-phase nitriding takes place, nitrogen absorption can occur in one or in two stages depending on the amount of liquid phase in the combustion wave. When forming large amount of combustion products (e.g. ferrovanadium) after melting, additional nitriding is absent. When fraction of liquid combustion products (e.g ferrosilicium) is lower, contribution of additional nitriding is significant.
\end{abstract}

Steel production in the world increases permanently. 1.7 bln t of steel was produced worldwide in 2018. More than 2 bln $t$ of ore, $\sim 1.2$ bln $t$ of coal, $\sim 0.2$ bln $t$ of lime and more than 0.06 bln $t$ of ferroalloys were used. This growth seems to be continued in the future, and load on the environment will increase. In general, ecological problems are very sharp today, and partly "thanks to" metallurgists. Increase of steel production can become unbearable load for the environment. At the same time, there is nor real alternative to steel now. Steel is the main structural material and this state will remain in the nearest decades. Despite increase of consumption of aluminium, titanium and other metals as well as plastic, ceramics and other structural materials, it is evident that Fe-based alloys will dominate in construction, transport, power engineering etc. Improvement of steel operating properties is considered as one of the ways for keeping the level of steel applications in order to support sustainable development of global economics without harmful impact on the environment. Rising strength and other metal physical and mechanical parameters, it is possible to decrease substantially metal's consumption together with improvement of operating characteristics of finished products and increase of their service life.

\footnotetext{
2 Gavrilova T. O., Deputy general director of NPTF

"Etalon", participated in this research.
}

(c) Shatokhin I. M., Ziatdinov M. Kh., Manashev I. R., ShiRyaev O. P., KARTUNOV A. D., 2019
Microalloying is one of the most efficient ways for achievement of the required level of steel operating properties. Both metals (V, Nb, Ti, Al et al.) and non-metals (N, B, P et al.) are used as microalloying elements. In this connection quality requirements to alloying materials become more strict. Chemical composition and structure of these materials should provide high and stable absorption of microalloying elements by steel melt. Exact proportioning of microalloying elements is required for efficient steel microalloying; it can be achieved only by controlled degree of microalloying elements absorption by melt with minimal consumption of alloying composition itself. Conventional furnace steel production technology is practically exhausted for microalloying. The new pulse for widening of alloys application for microalloying can be given by transition to composite ferroalloys. Stable optimal chemical composition of such alloys and composite structure guarantee obtaining of required concentration of microalloying elements in steel with minimal expenses. It is also important that microalloying elements in composite alloying compositions are presented as dispersed particles of refractory compounds: nitrides, borides, silicides etc. Synthesis of such composite materials is realized by the special method without usage of usual metallurgical furnaces; it is self-propagating high-temperature synthesis (SHS).

SHS of combustion synthesis is the national technological process suggested more than 45 years ago [1]. Usual SHS 


\begin{tabular}{|c|c|c|c|c|c|c|c|c|c|}
\hline Grade & & & $C$ & & & & & & \\
\hline & & & & & & & & & \\
\hline & $21100-94$ & 0.02 .4 & 0.00 & 1.9 & 0.01 & 0.00 & 0.1 & 3.0 & $\sigma$-vre \\
\hline PFN & $4757-91$ & Cr: 75.6 & 0.03 & 0.7 & 0.01 & 0.02 & 0.18 & - & $\mathrm{Cr}(\mathrm{Fe})$ \\
\hline FS75 & $1415-93$ & Si: 79.4 & 0.08 & 79.4 & 0.01 & 0.02 & 0.3 & 0.3 & $\mathrm{Si}, \mathrm{FeSi}_{2}$ \\
\hline FS65 & $1415-93$ & Si: 68.1 & 0.07 & 68.1 & 0.01 & 0.02 & 1.6 & 0.4 & $\mathrm{FeSi}_{2}, \mathrm{Si}$ \\
\hline FS45 & $1415-93$ & Si: 48.3 & 0.23 & 48.3 & 0.01 & 0.03 & 0.8 & 0.7 & $\mathrm{FeSi}_{2}, \mathrm{FeSi}$ \\
\hline
\end{tabular}

is conducted owing to heat emission as a result of exothermal synthesis reaction out of elements. SHS reactions are characterized by oxygen absence [2], other non-metals (C, B, N, $\mathrm{H}$ et al.) play the oxidizer role. SHS differs from usual oxygen combustion by absence of solid or gaseous wastes. SHS technology practically was not used in metallurgy due to high cost of powders of pure metals and non-metals [3, 4]. The problem of SHS technology usage in metallurgy was solved via development of "metallurgical SHS" process concept, where hard flame combustion is realized due to exchange exothermal oxygen-free reactions [5]. Ferroalloys, alloying compositions and alloys of nonferrous metals are the main raw material in synthesis of composite alloying materials. Their additional SHS processing allows to obtain new complex of properties and to provide their technological and economical efficiency [6-9].

Possibility of creation of SHS production of materials for metallurgy is displayed in this research on the example of synthesis of composite nitrogen-containing ferroalloys. This possibility is demonstrated on the examples of obtaining of alloying compositions on the base of $\mathrm{V}, \mathrm{Cr}$ and Si nitrides as the most required for steel microalloying by nitrogen. Nitrogen is known for more than 80 years as an alloying element. Nitrogen acceptability and practically endless natural reserves are its advantages. Its "mining" technology is not harmful for the environment and is not accompanied by forming of wastes. Nitrogen in natural form is gaseous and it is usually fixed in composition of ferroalloys for introduction in steel. Alloying using alloys is the main method of steel melting with nitrogen, owing to its universality, while nitriding technology using powder wire allows to increase degree of nitrogen absorption and to dose strictly its concentration.

\section{Materials and methods of research}

Standard ferroalloys were used as initial materials (Table 1).

Standard sieves were used for extraction of powders with required dispersity. Nitrogen and oxygen content was determined using LECO TCH-600 device. Phase composition of initial and synthesized alloys was determined with assistance of Shimadzu XRD 6000 diffractometer. Gaseous nitrogen with purity 99.95\% (GOST 9293-74) was used for nitriding. Combustion synthesis was conducted in the laboratorial SHS unit - the high pressure reactor [5]. Cylinder samples of two types (formed and not formed) were used in experiments. In the first case samples were manufactured via extrusion, in the second case - via charge of ferroalloy powder in a gas-permea- ble container made of steel net. Combustion temperature $\left(\mathrm{T}_{\Gamma}\right)$ was measured using W/Re 5/20 thermocouples. Thermocouple junction point was placed on the lower edge of the sample by depth $\sim 1.5 \mathrm{~cm}$.

\section{Results of the research and discussion}

Nitrogen is one of the reagents in synthesis of nitrided ferroalloys. This synthesis is realized in the form of filtration combustion that is characterized by strong relationship between combustion parameters and nitrogen pressure $\left(P_{\mathrm{N}_{2}}\right)$, powder dispersity $\left(d_{p}\right)$ and porosity of samples $\left(\Pi_{\text {obr. }}\right)[2,10]$.

\section{Synthesis of composite nitrided ferrovanadium}

There were many different steel grades containing V and $\mathrm{N}$ developed at present time. HSLA steels and rail steels are most widely applied [11]. NITROVAN alloy is mainly used abroad for melting of HSLA steels with $\mathrm{V}$ and $\mathrm{N}$ [12]. High concentration of impurities (S, C and other $)$, high melting temperature $\mathrm{T}_{\text {melt. }}\left(\sim 2400{ }^{\circ} \mathrm{C}\right)$ and low density $\left(2.5-3.0 \mathrm{~g} / \mathrm{cm}^{3}\right)$ are the factors restricting its application. Thereby NITROVAN is characterized by steel melt with low and unstable absorption of nitrogen and vanadium.

In Russia ferrovanadium with $\sim 50 \% \mathrm{~V}$ is the main source of vanadium for steel microalloying. It is produced via effective silicothermal reduction of vanadium technical pentoxide. The alloy presents intermetallic compound with $\sigma$-phase structure. Such ferrovanadium is brittle, thereby powder production for nitriding is not difficult.

Increase of nitrogen pressure and porosity of samples is accompanied by elevation of nitrogen concentration in combustion products (Fig. 1). Porosity of samples $56 \%$ corresponds to porosity of powder filling without thickening, while $39 \%$ corresponds to porosity of extruded samples. Extruded samples don't burn under pressure lower than $3 \mathrm{MPa}$ and non-extruded ones - under pressure lower than $0.5 \mathrm{MPa}$. Porosity of samples within ranges $36-46$ and $50-56 \%$ was obtained in formed samples via varying extrusion pressure and in non-extruded samples respectively. The samples with low porosity in combustion conditions are not nitrided. The lower is nitrogen pressure, the most narrow is porosity range within that combustion is possible. Increase of nitrogen pressure and porosity of samples finalize in improvement of filtration conditions during combustion, what leads to elevation of nitrogen amount fixed in synthesis products. 

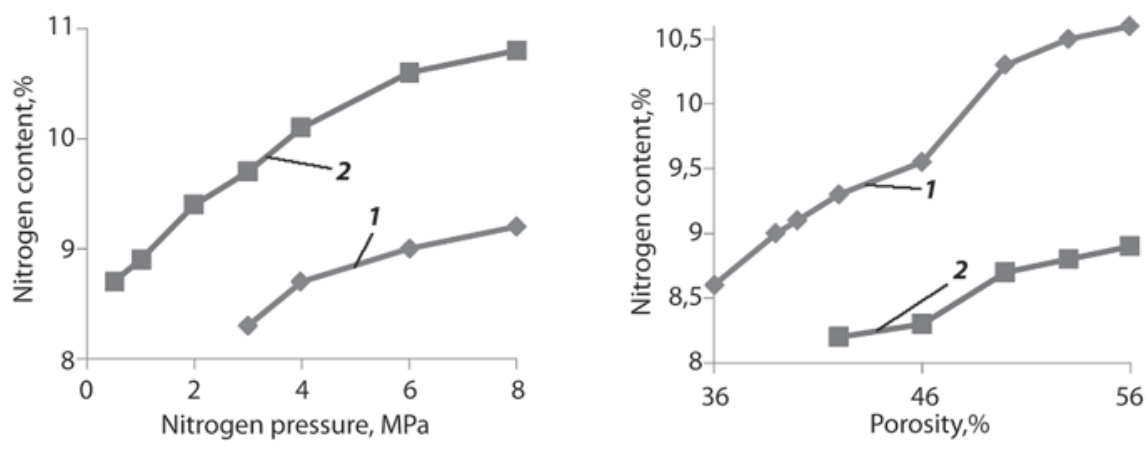

section was fabricated from such sample. We can observe that maximal temperature $\left(T_{\mathrm{\Gamma}}\right)$ is reached very quickly $(\sim 0,1$ $\mathrm{s})$. The process of transformation of initial ferrovanadium powder $(\sigma-\mathrm{FeV})$ in composite product $(\delta-\mathrm{VN}+\alpha-\mathrm{Fe})$ takes approximately the same time. So-called "explosive" nitriding as a result of $\sigma \rightarrow \alpha$ reaction [5] promotes to form practically porous-free composite structure. Accelerated consolidation is the cause of absence of ad-
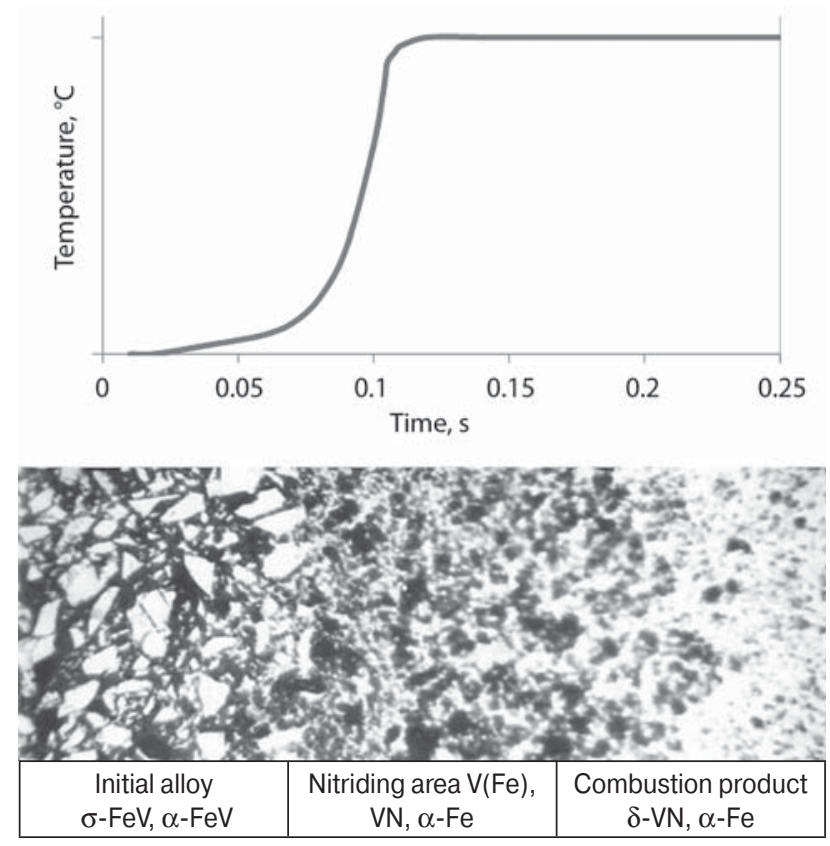

Fig. 2. Typical temperature profile of ferrovanadium nitriding and structure of combustion area, size of particles less than $50 \mu \mathrm{m}$

Ferrovanadium powders of different fractions were subjected to nitriding. Polydispersed powder of initial ferrovanadium was screened through sieves with cell sizes 50 , 100,160 and $315 \mu \mathrm{m}$. Non-extruded samples with different dispersity were nitrided under pressure 1 and $6 \mathrm{MPa}$. Nitriding of more coarse powder was possible at higher pressure. Nitriding of powder with dispersity $-315 \mu \mathrm{m}$ could not be realized in combustion conditions. Increase of sizes of particles leads to slight elevation of nitriding degree: from 8.8 to 9.4 at $1 \mathrm{MPa}(-50$ and $-00 \mu \mathrm{m})$ and from 10.6 to 11.5 at $6 \mathrm{MPa}(-50$ and $-160 \mu \mathrm{m})$.

Temperature of ferrovanadium combustion in nitrogen varies within the range $1480-1560{ }^{\circ} \mathrm{C}$ depending on the process conditions. It correlates with nitrogen content in combustion products. Typical temperature profile obtained using thermocouple is presented on the Fig. 2.

It is coincided with the structure of combustion area, fixed by quenching of combustion sample. The polished ditional reacting in ferrovanadium nitriding. Nitrogen absorption during nitriding of metals and ferroalloys can occur step-by-step. Stadiality is fixed during combustion of samples in the special SHS unit with continuous registration of their weight. Single-stage nitriding is realized in ferrovanadium combustion. Ferrovanadium samples after combustion are characterized by molten structure with porosity less than $10 \%$.

\section{Ferrochromium nitriding}

At present time nitrided ferrochromium is used for melting of wide range of stainless steels. Melting of austenite stainless steels on $\mathrm{Cr}-\mathrm{Mn}$ and $\mathrm{Cr}-\mathrm{Mn}-\mathrm{Ni}$ bases are considered as the most stable technologies in this field. Different variants of these steels are included in standards. So-called "200 series" (UNS20100, UNS20200, UNS20500 etc.) are widely used. Maximal number of nitrogen-containing stainless steels is melted today in the countries with the most dynamically developed metallurgy (China, India and other). Chromium-manganese nitrogen-containing steels are used in construction, transport, chemical and food industry, for manufacture of the components for automobiles, household appliances, dishes etc. In addition to 200 series steels that are widely used, high-nitrogen steels for special usage are developed and applied. They become practically having no alternative owing to their unique properties. The following steels are the bright examples: 08-12Kh18AG18 steel with $\sim 0,5 \% \mathrm{~N}$ for fabrication of shroud rings for turbines generators, heat-resistant 55Kh21G9AN4 steel with $0,3-0,6 \% \mathrm{~N}$ for drive valves of automobiles, as well as steel for operation in cryogenic conditions and in sea water. Only nitriding can practically provide achieving of simultaneous increase of metal strength, toughness and corrosion resistance [13, 14].

The powder of aluminothermal ferrochromium, most pure from impurities, was used for nitriding. Ferrochromium powder $\left(d_{p} \leq 0.02 ; 0.04\right.$ and $\left.0.08 \mathrm{~mm}\right)$ was combusted without consolidation in gas-permeable shells from steel net. Combustion in extruded samples could not be initiated at nitrogen pressure below $10 \mathrm{MPa}$. It is caused by low reaction exothermity of 

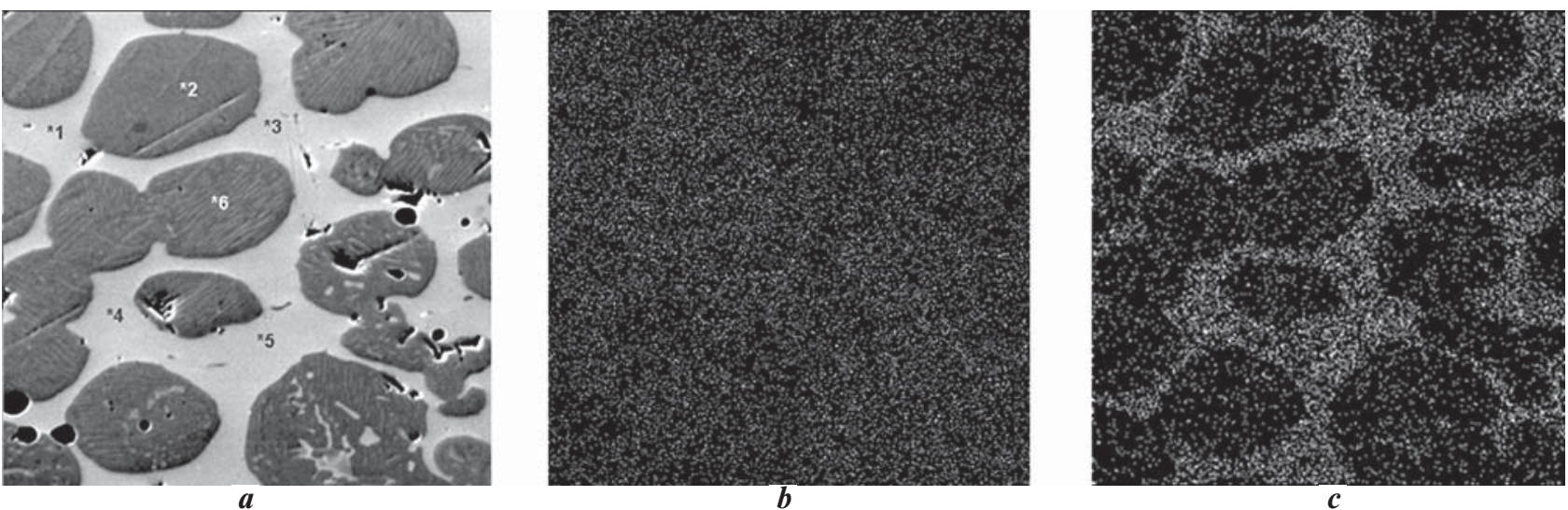

Fig. 3. Microstructure and microanalysis of nitrided ferrochromium

forming of chromium nitrides. Interaction between ferrochromium and nitrogen in combustion wave is realized in accordance with solid phase mechanism. Low-carbon ferrochromium is melted at $1550-1670{ }^{\circ} \mathrm{C}$. Temperature of liquid phase appearance in the system $\mathrm{Cr}-$

\begin{tabular}{|l|c|c|c|c|c|c|}
\hline \multicolumn{7}{|c|}{ Table 2. Microanalysis results of nitrided ferrochromium (Fig. 3, c) } \\
\hline & 1 & 2 & 3 & 4 & 5 & 6 \\
\hline $\mathrm{Cr}(a)$ & 57.7 & 82.8 & 66.6 & 66.1 & 57.6 & 78.1 \\
\hline $\mathrm{Fe}(b)$ & 33.1 & 6.3 & 25.5 & 27.5 & 33.5 & 13.3 \\
\hline $\mathrm{N}$ & 3.4 & 10.7 & 3.8 & 2.0 & 3.1 & 7.2 \\
\hline $\mathrm{Phases}$ & $\mathrm{Cr}(\mathrm{Fe}, \mathrm{N})$ & $\left(\mathrm{Cr}_{x} \mathrm{Fe}_{y}\right)_{2} \mathrm{~N}$ & $\mathrm{Cr}(\mathrm{Fe}, \mathrm{N})$ & $\mathrm{Cr}(\mathrm{Fe}, \mathrm{N})$ & $\mathrm{Cr}(\mathrm{Fe}, \mathrm{N})$ & $\left(\mathrm{Cr}_{x} \mathrm{Fe}_{y}\right)_{2} \mathrm{~N}$ \\
\hline
\end{tabular}
$\mathrm{Fe}-\mathrm{N}$ is higher than combustion temperature, which made $1220-1300{ }^{\circ} \mathrm{C}$ compared with calculated temperature $\sim 1680{ }^{\circ} \mathrm{C}$ within the range $P_{\mathrm{N}_{2}}=$ $=2.0-10.0 \mathrm{MPa}$. Rise of initial temperature $\left(T_{0}\right)$ accompanies by increase of ferrochromium combustion rate. More coarse ferrochromium powders $\left(d_{p} \leq 0,2 \mathrm{~mm}\right)$ are nitrided at the temperature $T_{0} \geq 400{ }^{\circ} \mathrm{C}$. Solid phase mechanism promotes achieving the high nitriding degree. Calculated nitrogen concentration is $16.9 \%$ for the alloy containing $75.6 \% \mathrm{Cr}$, while actually achieved nitrogen concentration was $\sim 14.2 \% \mathrm{~N}$. The most fine is powder, the larger is ferrochromium nitriding degree. Nitrided ferrochromium is characterized by composite structure containing of $\left(\mathrm{Cr}_{x} \mathrm{Fe}_{y}\right)_{2} \mathrm{~N}$ nitride and nitrogen solid solution in $\mathrm{Cr}(\mathrm{Fe}, \mathrm{N})$ ferrochromium (Fig. 3, Table 2).

Ferrochromium nitriding occurs in filtration procedure. Chemical composition of initial materials, size of particles of nitriding alloy, permeability of powder filling, nitrogen pressure and conditions of its delivery in reaction area are the main parameters. Ferrochromium nitriding in combustion procedure is realized in solid phase. Combustion temperature is restricted by $\mathrm{CrN}$ dissociation temperature. It is possible to obtain nitride with $8.8-14.2 \% \mathrm{~N}$ in ferrochromium nitriding.

\section{Ferrosilicium nitriding}

Regularities of ferrosilicium nitriding in combustion procedure are close to regularities of silicon combustion [15]. Ferrosilicium is melting at lower temperature than metal-

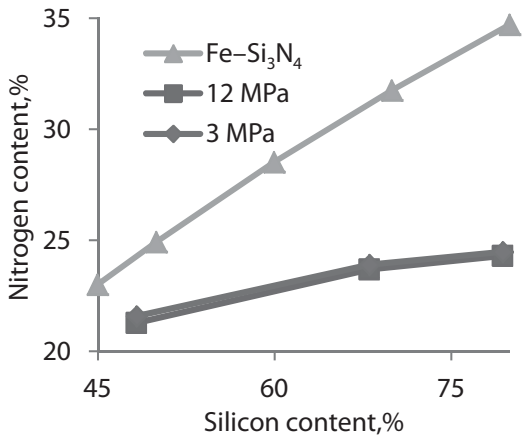

a lic silicon. Alloys containing 40-80\% Si begin melting at the heating temperature more than $1210{ }^{\circ} \mathrm{C}$. Thereby the effects stipulated by liquid phase forming appear stronger. Ferrosilicium, as well as ferrovanadium and ferrochromium, is nitrided in filtration procedure. In this case combustion regularities as well as composition and structure of synthesis products depend strongly on working gas pressure, charge metaerial permeability, introduction of additional components in charge material, their chemical and phase composition, level of initial heating of primary mixture, presense of liquid phases in charge materials and combustion products. The relationships between heating degree and nitrogen amount in ferrosilicium combustion products (from one side) and silicon concentration (from other side) confirm these observations (Fig. 4). Rise of silicon content in the alloy leads to increase of its activity. Ferrosilicium reacts with nitrogen more intensively and combustion rate increases significantly as a result of

Fig. 4. Influence of silicon concentration in ferrosilicium on nitrogen content $(a)$ and combustion temperature $(b), d_{p} \leq 0,08 \mathrm{~mm}$ : 1 - calculation; 2- $12 \mathrm{MPa} ; 3-3 \mathrm{MPa}$ 
this reaction. Nitrogen concentration in combustion products also increases in this case, while part of silicon transformed in nitride decreases as soon as Fe content in the alloys lowers. At the same time increase of nitrogen pressure leads to only slight elevation of combustion temperature of ferrosilicium alloys. More high silicon content in ferrosilicium leads to fixing of more nitrogen amount in combustion products. Increase of nitrogen pressure is connected with slight elevation of combustion temperature for all ferrosilicium grades. The more silicon amount is transformed in nitride, the higher is combustion temperature. If pressure is within the range $1.0-12.0 \mathrm{MPa}$, degree of silicon transformation in nitride is far from maximal values. Heating process achieving during ferrosilicium combustion in nitrogen is rather higher than its melting temperature. Melting of FS65 and FS75 ferrosilicium starts approximately at $1200{ }^{\circ} \mathrm{C}$, and they are completely liquid at the temperature above $1300-1350{ }^{\circ} \mathrm{C}$. Analysis of microstructure of the samples that were combusted not completely confirms that intensive coagulation of molten ferrosilicium particles occurs in combustion wave. As a result, reactional surface decreases and it leads to incomplete silicon transformation in nitride.

Nitriding of ferrosilicium occurs slowly: combustion rate $U_{2}=0.55-0.60 \mathrm{~mm} / \mathrm{s}$ at $P_{\mathrm{N}_{2}}=12.0 \mathrm{MPa}$. It is caused by low nitrogen solubility in solid and liquid silicon, by low diffusion movability of $\mathrm{N}$ and $\mathrm{Si}$ atoms, by low heat conductivity of silicon nitride $\mathrm{Si}_{3} \mathrm{~N}_{4}$ and ferrosilicium alloys. The larger is the size of alloy particles, the less nitrogen amount is fixed in combustion products owing to incomplete silicon transition in nitride.

Nitrogen filtration is created due to difference of pressures in the reaction area and in external space. Nitrogen is permanently absorbing and pressure in the reaction area decreases. Thereby the reaction area is operated as a chemical pump, drawing gas in a combustion wave. The larger is porosity, the most effective is filtration and the best conditions are created for combustion. Saving of samples permeability and incompleteness of silicon transition in nitride directly in a synthesis wave during combustion are the required conditions for creation of additional nitriding stage. Porosity of combustion products makes 35-55\%. Analysis of chemical composition of samples quenched by sudden interruption of combustion allowed to reveal that substantial increase of nitrogen concentration in these samples occurs during additional nitriding. The large input of additional nitriding stage is a cause of weak relationship between nitrogen content in combustion products and nitrogen pressure.

The main phase containing in nitrided ferrosilicium is $\beta-\mathrm{Si}_{3} \mathrm{~N}_{4}$. Essential amount of $\alpha-\mathrm{Si}_{3} \mathrm{~N}_{4}$ were not revealed. Silicon amount transformed in the nitride $\left(\mathrm{Si} \rightarrow \mathrm{Si}_{3} \mathrm{~N}_{4}\right)$ makes the most influence on phase composition. The composite product on the base of $\beta-\mathrm{Si}_{3} \mathrm{~N}_{4}(60-85 \%)$ is forming after nitriding in combustion procedure. In the case of complete silicon transformation in nitride, $\alpha-\mathrm{Fe}$ will be a binder for it, and in the case of low (incomplete) transformation - its silicides.

Volumetric part of nitride exceeds $90 \%$ owing to high silicon content in the initial alloy and large difference in density of its main ingredients ( $\mathrm{Si}$ and $\mathrm{Fe}$ ) in the composition synthesized from FS75 alloy. In this case Fe is distributed in the volume in the form of separate islands with size up to $\sim 200 \mu \mathrm{m}$. Their forming occurs due to coalescence of Fe melt and its silicides.

Therefore, SHS method allows to synthesize the composite alloy on the base of $\mathrm{Si}_{3} \mathrm{~N}_{4}$, using all ferrosilicium grades as initial material. They are based on the most thermally stable silicon nitride of $\beta$-modification. This form of $\mathrm{Si}_{3} \mathrm{~N}_{4}$ is the most effective for application in notch and gutter masses and as a component of alloying materials. In practical usage, FS57 alloy is optimal for refractories production, while FS65 alloy grades (the most pure for impurities) are the most suitable for steel alloying.

In the beginning of 2000-ies the process of transformer steel production was started at Magnitogorsk Iron and Steel Works and at "VIZ-stal" enterprise. Metal was melted in $350 \mathrm{t}$ basic oxygen converters with consequent continuous casting in $16 \mathrm{t}$ slabs and rolling in 2000 wide hot strip mill. Obtaining of the required nitrogen content $(0,009-0,012 \%)$ as the key alloying element was one of the most complicated stage of the new steel production technology. It is just nitrogen that forms nano-sized aluminium nitrides and allows to obtain the unique rib texture during heat treatment that defines high magnetic parameters of the metal. Usage of composite nitrided ferrosilicium $\left(\mathrm{Si}_{3} \mathrm{~N}_{4}-\mathrm{FeSi}-\mathrm{Fe}\right)$ of NITROFESIL ${ }^{\circledR} \mathrm{A}$ grade, developed by NTPF "Etalon", became solving of this problem. At present time all transformer metal in Russia id manufactured via microalloying with this nitrided ferrosilicium. Alloying composition is added in bulk form in a ladle during metal pouring for preliminary metal alloying by nitrogen before ladle treatment. Its required content in finished steel is obtained by correction with powder wire with the same alloying composition. This technology provides production of steel grades with the highest nitrogen content in ladle sample on the level $80-90 \%$ and in rolled billets $-100 \%$. Narrow boundaries of nitrogen concentration provide production of finished sheet metal with high quality of magnetic properties level (within 92-95\%).

At present time Novolipetsk Iron and Steel Works (NLMK) uses the experience of Magnitogorsk Iron and Steel Works (MMK) in melting of transformer steel in basic oxygen converters and applies powder wire with nitrided ferrosilicium as a filler for correction of nitrogen content. It allows to decrease deviation of nitrogen content in steel in the conditions of converter shop at NLMK (Fig. 5).

The new variant of steel modification by nitrogen was put into practice at the Russian enterprises since 2005. It is based on introduction of silicon nitride in a ladle using pinch rolls, what allowed to fix finally the 


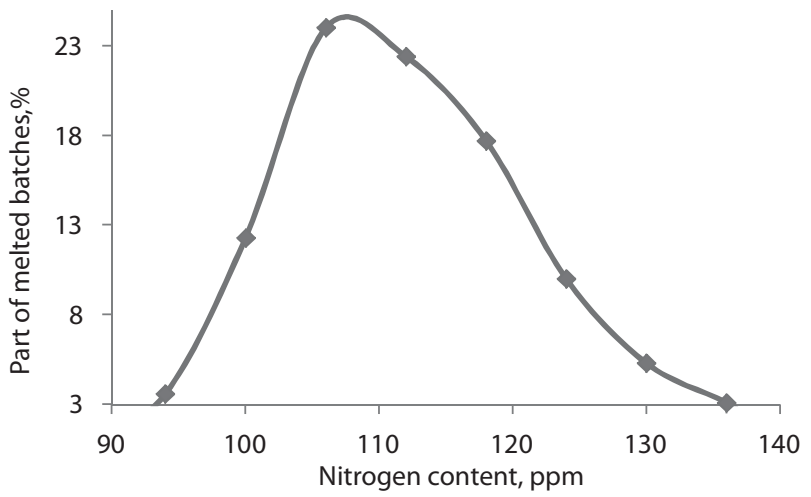

Fig. 5. Distribution of nitrogen content in steel

advantages of nitride option by the level of magnetic properties (lowering of losses $\mathrm{P}_{1.7 / 50}$ made $0.09 \mathrm{Wt} / \mathrm{kg}$ for strip thickness 0.27 and $0.23 \mathrm{~mm}$ ), by decrease of consumption ratio (from 1.24 to $1.12 \mathrm{t} / \mathrm{t}$ ) and by diminishing of electric power consumption (from 2.83 to $2.00 \mathrm{MWt} \cdot \mathrm{h} / \mathrm{t}$ ).

\section{Conclusions}

The ways of improvement of SHS production of materials for metallurgy were displayed on the example of composite nitrogen-bearing ferroalloys on the base of $\mathrm{V}, \mathrm{Cr}$ and $\mathrm{Si}$ nitrides. It is shown that use of standard ferroalloys of domestic production as raw materials makes it possible to synthesize composite alloying compositions combining high nitrogen content and high density. The new composite ferroalloys were successfully tested in pilot-industrial conditions at the Russian metallurgical works. So, composite nitrided ferrovanadium was tested in melting of high-strength low-alloyed (HSLA) and rail steels at EVRAZ NTMK, MMK etc., composite nitrided ferrochromium was tested in melting of different grades of stainless steels ("Elektrostal", "Ruspolimet" etc.) and composite nitrided ferrosilicium was tested in melting of transformer steel (NLMK, MMK).

\section{REFERENCES}

1. Merzhanov A. G., Borovinskaya I. P. Self-propagating high-temperature synthesis of refractory inorganic compounds. Doklady AN SSSR. 1972. Vol. 204. Pp. 366-369.

2. Merzhanov A. G. Scientific grounds, achievements and development prospects of the processes of solid flame combustion. Izvestia RAN. Seriya khimicheskaya. 1997. Vol. 46. No. 1. pp. 7-31.

3. Levashov E. A., Mukasyan A. S., Rogachev A. S., Shtansky D. V. Self-propagating high-temperature synthesis of advanced materials and coatings. International Materials Reviews, 2017. Vol. 62. No. 4. pp. 203-239.

4. Mukasyan A. S., Rogachev A. S, Aruna S. T. Combustion synthesis in nanostructured reactive systems. Advanced Powder Technology. 2015. Vol. 26. No. 3. pp. 954-976.
5. Ziatdinov M. Kh., Shatokhin I. M., Leontyev L. I. SHS Technology for Composite Ferroalloys. 1. Metallurgical SHS: Nitride of Ferrovanadium and Ferrochromium. Steel in Translation. 2018. Vol. 48. No. 5. pp. 269-276.

6. Maksimov Y. M., Ziatdinov M. Kh., Merzhanov A. G., Raskolenko L. G., Lepakova O. K. Combustion of vanadium-iron alloys in nitrogen. Combustion, Explosion, and Shock Waves. 1984. Vol. 20. Iss. 5. pp 487-492.

7. Chukhlomina L. N., Maksimov Yu. M., Kitler V. D., Vitushkina O.G. Mechanism and features of nitriding of ferrosilicon in the combustion regime. Combustion, Explosion, and Shock Waves. 2006. Vol. 42. Iss. 3. pp 309-316.

8. Braverman B. Sh., Maksimov Yu. M., Tsybulnik Yu. V. Possibility of Nitriding Industrial Ferroalloys in a Nitrogen-Containing Gas Flow. Combustion, Explosion, and Shock Waves. 2012. Vol. 48. Iss. 6. pp. 34-35.

9. Bolgaru K. A., Chukhlomina L. N., Maksimov Y. M. Study of regularities for the nitriding of complex ferrosilicoaluminum ferroalloy during SHS. Izvestiya vuzov. Poroshkovaya metallurgiya i funktsional'nye pokrytiya. 2016. Vol. 4. pp. 34-40.

10. Munir Z. A., Holt J. B. The combustion synthesis of refractory nitrides. Part 1. Theoretical analysis. Journal of Materials Science. 1987. Vol. 22. Iss. 2. pp. 710-714.

11. Chukin M. V., Poletskov P. P., Nikitenko O. A., Nabatchikov D. G. Study of Microstructure of Rolled heavy Plates Made of Low-alloyed Pipe Steel with Increased Strength and Cold Resistance. CIS Iron and Steel Review. 2017. Vol. 13. pp. 28-32.

12. Tian P., Zhong Z. Y., Bai R. G., Zhang X. L., Gao H. Application of Different Vanadium Alloys in Steel. Proceedings of the International Conference on Computer Information Systems and Industrial Applications (CISIA 2015). Bangkok, Thailand on June 28-29, 2015. pp. 861-864.

13. Hanninen H. E. Application and Performance of high Nitrogen Steels. Steel GRIPS. 2004. No. 2. pp. 371-380.

14. Kaputkina L. M., Svyazhin A. G., Smarygina I. V., Kindop V. E. Influence of Nitrogen and Copper on Hardening of Austenitic Chromiumnickel-manganese Stainless Steel. CIS Iron and Steel Review. 2016. Vol. 11. pp. 30-34.

15. Mukasyan A. S., Merzhanov A. G., Martinenko V. M., Borovinskaya I. P. Blinov M. Y. Mechanism and Principles of Silicon Combustion in Nitrogen. Combustion Explosion Shock Waves. 1986. Vol. 22. No. 5. pp. 534-540.

16. Ziatdinov M. Kh., Shatokhin I. M., Leontyev L. I. SHS Technology for Composite Ferroalloys. 2. Synthesis of Ferrosilicon Nitrides and Ferrotitanium Boride. Steel in Translation. 2018. Vol. 48. No. 7. pp. 411-418.

17. Shatokhin I. M., Ziatdinov M. Kh., Smirnov L. A., Manashev I. R. Nitrided Ferroalloy Production By Metallurgical SHS Process: Scientific Foundations and Technology. Theoretical and practical conference with international participation and School for young scientists "FERROALLOYS: Development prospects of metallurgy and machine building based on completed Research and Development”. KnE Materials Science. 2019. pp. 191-206. DOI: 10.18502/ kms.v5i1.3969 